\title{
Efficient Removal of Two Typical Anionic Dyes from Aqueous Solution by the Novel Polymer Hydrogels
}

\author{
WEIXIA ZHU ${ }^{1}$, SHUN YAO $^{2}$, ZHENGBO HOU $^{2}$ and HANG SONG ${ }^{2 *}$ \\ ${ }^{1}$ School of Chemical Engineering Energy, Zhengzhou University, Zhengzhou, 450001, China \\ ${ }^{2}$ School of Chemical Engineering, Sichuan University, Chengdu, 610065, China \\ hangsong@scu.edu.cn.
}

Received 19 July 2016 / Accepted 3 September 2016

\begin{abstract}
Poly( $N, N$ dimethylaminoethyl methacrylate) hydrogels (PDMAEMA) were optimized by pore-forming and copolymerization with polyethyleneimine (PEI) and the macroporous PDMAEMA together with the composite materials PEI/PDMAEMA were synthesized to remove anionic dyes from aqueous solution for the first time. The physicochemical properties of these materials were investigated by Fourier transform infrared spectroscopy (FT-IR), elemental analysis (E.A), thermogravimetric analysis (TGA) and scanning electron microscope (SEM). The adsorption behaviors of PDMAEMA, macroporous PDMAEMA and PEI/PDMAEMA for sunset yellow FCF and amaranth were compared. The results showed that the adsorption rate of macroporous PDMAEMA was faster than that of PDMAEMA, and the adsorption capacity was nearly unchanged; but for PEI/PDMAEMA, both adsorption rate and adsorption capacity were improved. The maximum adsorption capacity of PEI/PDMAEMA could reach $744.14 \mathrm{mg} / \mathrm{g}$ for SY FCF and $757.10 \mathrm{mg} / \mathrm{g}$ for amaranth, and the saturation adsorption time were both $1 \mathrm{~h}$. The adsorption isotherms and kinetics were well fitted by Langmuir model and pseudo second-order model, respectively, and the adsorption mechanism was explained by electrical double layer theory. In addition, the desorption ratio of above $92 \%$ indicated that these adsorbing materials could be regenerated successfully for recycle and reuse. In a word, ED hydrogels have the excellent adsorption capability and could be employed as a new potential useful adsorbent for the decontamination and analysis of wastewater containing anionic dyes in large scale.
\end{abstract}

Keywords: Polyethyleneimine, Polymers hydrogels, PEI/PDMAEMA, Anionic dyes, Adsorption

\section{Introduction}

Dyestuff wastewater from textile, electroplating, tannery and food industry has become an increasingly prominent issue. Even a small amount of dyes in the natural aquatic system can bring tremendous harm to people and environment because of their undesirable color, high chemical oxygendemand, high salt content, carcinogenic and mutagenic effects ${ }^{1-4}$. Nowadays, some methods including biological treatment, chemical precipitation, coagulation, 
solvent extraction, membrane filtration, adsorption etc., have been used to treat dye wastewater ${ }^{1,4}$. Among all these methods, adsorption is recognized as a very appealing way because of its easy availability, simplicity of design, amity to environment, high selectivity and efficiency, easy operation and recycling, etc. ${ }^{4,5}$. In recent years, many novel adsorbents have been developed, such as polystyrene ${ }^{6}$, lanatus rind $^{7}$, chitosan $^{8}$, mangrove barks $^{9}$, polymer $^{10}$, hydroxides ${ }^{11}$.

Poly $(N, N$-dimethylaminoethyl methacrylate) (PDMAEMA) hydrogel, a cationic polymer, has received considerable attention because of the excellent adsorption ability. Tokuyama et al., ${ }^{12}$ investigated that the adsorption capabilities of poly(2-(dimethylaminoethyl)methacrylate) gels for $\mathrm{Pt}(\mathrm{IV})$ and $\mathrm{Au}(\mathrm{III})$ were $0.2542 \mathrm{mmol} / \mathrm{g}$ and $0.2351 \mathrm{mmol} / \mathrm{g}$, respectively, and the adsorption amount could be adjusted by temperature-swing. Dilek Solpan et al. ${ }^{13}$ successfully synthesized the ternary mixtures of DMAEMA/ ethyleneglycol dimethacrylate (EGDMA)/water $\left(\mathrm{H}_{2} \mathrm{O}\right)$. The maximum adsorption values of Apollofix Red (AR) and Apollofix Yellow (AY) on the ternary mixtures are $131 \mathrm{mg} / \mathrm{g}$ and $111 \mathrm{mg} / \mathrm{g}$, respectively. Although the adsorption capacity of PDMAEMA is better than the traditional adsorbents, there are still some shortcomings. On the one hand, the adsorption process is time-consuming. It took seven days to reach the adsorption balance in previous application for precious metal ions ${ }^{12}$. Cheng et al. also reported that the pore structure of PDMAEMA limited the adsorption rate ${ }^{14}$. On the other hand, the adsorption ability can still be imoproved remarkably. Yu et al. reported that Poly $(m$-phenylenediamine) (PmPD) with different oxidation possessed the highest $\mathrm{Cr}(\mathrm{VI})$ removal $^{15}$ of $500 \mathrm{mg} / \mathrm{g}$. Gao et al., modified PDVB with IL and the adsorption amount of orange II, sunset yellow FCF, and amaranth were up to $925.09,734.62$, and $547.17 \mathrm{mg} / \mathrm{g}$, respectively ${ }^{10}$. Therefore, it is necessary to optimize the structure and make further improvement on the adsorption capacity and efficiency of PDMAEMA.

In the present work, PDMAEMA was firstly optimized by pore-forming using $\mathrm{Na}_{2} \mathrm{SO}_{4}$ as the porosity-making agent and copolymerizing with polyethylenimine (PEI) to improve the hydrophilicity and the amount of amide groups. The potential of macroporous PDMAEMA and PEI/ PDMAEMA for removing Sunset yellow FCF (SY FCF) and Amaranth (AM) was investigated, focusing on the five main objectives: (1) to prepare macroporous PDMAEMA and PEI/PDMAEMA; (2) to characterize the macroporous PDMAEMA and PEI/ PDMAEMA by Fourier transform infrared spectroscopy (FT-IR), elemental analysis (E.A), thermogravimetric analysis (TGA) and scanning electron microscope (SEM); (3) to compare the adsorption rate and amount of macroporous PDMAEMA and PEI/PDMAEMA for SY FCF and AM; (4) to further elucidate the adsorption mechanisms; (5) to evaluate the desorption and regeneration performance of macroporous PDMAEMA and PEI/ PDMAEMA.

\section{Experimental}

$N, N$-dimethylaminoethyl methacrylate (DMAEMA) monomer, $N, N$ '-methylenebisacrylamide (MBAA) cross-linker and azodiisobutyronitrile (ABN) initiator were purchased from Puguang industrial Co., Ltd. (Shanghai, China). Polyethyleneimine (PEI)(Mw $=1800 \mathrm{~g} \mathrm{~mol}^{-1}$, $25 \%$ aqueous solution, the content of primary, secondary and tertiary amino groups are $35 \%$, $35 \%$ and $30 \%$, respectively.) was obtained from Mengde electroplate chemistry Co., Ltd. (Jiangsu, China). Sunset yellow FCF (SY FCF) and Amaranth (AM) were supplied by Aladdin (Shanghai, China) and Kelong (ChengDu, China). $\mathrm{Na}_{2} \mathrm{SO}_{4}$ was provided by Hangjia Bio-Pharm (Sichuan, China). Other reagents were all analytical grade and all solutions were prepared with distilled water. 


\section{Preparation of Hydrogels}

PDMAEMA and macroporous PDMAEMA hydrogels were prepared according to our previous report ${ }^{16}$ and the macroporous gels were obtained in $5 \mathrm{wt} \% \mathrm{Na}_{2} \mathrm{SO}_{4}$ solution in this study. Composite material PEI/PDMAEMA was synthesized by amino radical polymerization. The process was as follows. $1 \mathrm{~mol} / \mathrm{L}$ of DMAEMA, $0.05 \mathrm{~mol} / \mathrm{L}$ of MBAA, $0.005 \mathrm{~mol} / \mathrm{L}$ of $\mathrm{ABN}$ were dissolved in $3 \mathrm{~mL}$ ethanol solution, respectively and then mixed with PEI solution with the mass concentration of $5 \mathrm{wt} \%$. The mixtures were stirred in nitrogen atmosphere for $10 \mathrm{~min}$ and rapidly poured into tubes with $6 \mathrm{~mm}$ inner diameter. Then, the tubes were sealed and submerged in thermostatic water bath for $3 \mathrm{~h}$ at different temperatures. Finally, the PEI/PDMAEMA gels were rapidly cooled to room temperature and cut into cylinders. The cylinders were extracted with $95 \%$ ethanol, until little PEI residual was obtained from the extracted liquid. The PDMAEMA, macroporous PDMAEMA and PEI/ PDMAEMA were marked as PD, MD and ED, respectively.

The amount of PEI in the adsorbent (GY) was determined by element analysis. According to the content of elements, GY can be calculated as following:

$$
G Y(\%)=\frac{W_{P E I}}{W_{P D M A E M A}} x 100 \%
$$

Where $W_{P E I}$ and $W_{P D M A E M A}$ are the PEI and PDMAEMA weight percentage on the PEI/PDMAEMA material, respectively, which are calculated from the results of the element analysis.

\section{Characterization of hydrogels}

PD, MD and ED were characterized by Spectrum One FT-IR (Perkin-Elmer, USA) using KBr disc. The spectra were recorded in the absorbance mode at wave number range of $4000 \sim 400 \mathrm{~cm}^{-1}$.

The morphology of PD, MD and ED were observered using JEM-100CX-II scanning electron microscope (SEM) (JEOL, Japan). Elemental analyses were accomplished with 2400 Series II CHNS/O Elemental Analyzer (PerkinElmer, USA). Zeta potential was measured with a JS94G+ microelectrophoresis apparatus (Zhongyiyuanda, China).

\section{Adsorption experiments}

The adsorption of anionic dyes (SY FCF and AM) on the adsorbent was investigated via static adsorption experiments. All adsorption experiments were carried out with $50 \mathrm{~mL}$ of dyes solutions. The adsorption conditions such as time, temperature, concentration (200$1600 \mathrm{mg} / \mathrm{L}), \mathrm{pH}$ and ionic strength were studied. The concentration $\left(C_{t}\right)$ in supernatant was determined by TU1810SPC UV-Vis spectrophotometer (Puxitongyong Instrumental Co., Ltd., China) at $482 \mathrm{~nm}$ and $521 \mathrm{~nm}$ for SY FCF and AM anions, respectively. The adsorption amount of anionic dyes $(Q, \mathrm{mg} / \mathrm{g})$ was calculated according to the following equation:

$$
\text { Adsorption capacity }(\mathrm{Q})=\frac{\mathrm{Vx}\left(\mathrm{C}_{0}-\mathrm{C}_{\mathrm{t}}\right)}{W}
$$

Where, $C_{0}$ and $C t$ are the concentrations of dye before and after adsorption, $W(g)$ and $V$ (L) stand for the weight of the gel and the volume of solution added respectively. The anionic dyes removal percentage can be determined by the equation below:

$$
\text { Removal rate }(R r)=\frac{C_{0}-C_{t}}{C_{0}} \times 100 \%
$$


The data of the adsorption kinetic and isotherm were obtained via adjusting the different parameters. In addition, for researching the influence of $\mathrm{pH}$ value on the adsorption amount, the solution $\mathrm{pH}$ was adjusted by $1 \mathrm{~mol} / \mathrm{L} \mathrm{HCl}$ or $1 \mathrm{~mol} / \mathrm{L} \mathrm{NaOH}$ and monitored by a $\mathrm{pH}$ meter (Yulong Instrument Co., Ltd., China).

\section{Desorption experiment}

The hydrogels used for desorption experiment were equilibrated with the adsorbate in the dyes solution with an initial concentration of $200 \mathrm{mg} / \mathrm{L}$ beforehand. Then the filtered compounds were put into $5 \mathrm{~mL}$ of $0.1 \mathrm{~mol} / \mathrm{L} \mathrm{NaOH}$ solution for $30 \mathrm{~min}$ at room temperature, which was repeated once to ensure sufficient cleanliness. Finally, the amount of dyes in the eluent was analyzed by the same way as mentioned above. The desorption ratio $(D r)$ is defined by the following equation:

$$
\text { Desorption rate }(D r)=\frac{C x V}{Q x W} \times 100 \%
$$

Where $C(m g / L)$ and $V(L)$ are the concentration of adsorbates in the desorption solution and volume of the desorption solution, respectively. $Q(\mathrm{mg} / \mathrm{g})$ and $W(\mathrm{mg})$ own the identical meaning as mentioned above.

\section{Results and Discussion}

\section{Characterization}

The copolymerization of PEI on the polymer network was firstly proved by extraction method, and the chopped sample of PEI/PDMAEMA was extracted with for 30 min (solidliquid ratio=1:30, g/mL) under ultrasound wave $(20 \mathrm{kHz})$ and refluxing, respectively. If PEI was physically mixed in the product of copolymer, it would be extracted from the solid mixture and dissolved in the ethanol. After the removal of solvent under vacuum, the same results were observered and little residual was obtained from the extracted liquid, which indicated PEI has been chemically grafted on the network stably. In Figure 1(a), all the FTIR spectra of PD, MD and ED own the characteristic absorption of PDMAEMA ${ }^{17}$. The sharp peak at $1727 \mathrm{~cm}^{-1}$ is due to the stretching of the -COO- bond. The absorption band of 3000 2900 $\mathrm{cm}^{-1}$ belongs to dimethyl amino groups in their structure. Aliphatic C-N stretching band of DMAEMA can be observed at $1177 \mathrm{~cm}^{-1}$. And the strong and wide peak at $3437 \mathrm{~cm}^{-1}$ could be caused by the residual water. The difference between ED curve and other ones is the notable characteristic $\mathrm{N}-\mathrm{H}$ amino stretching bands at 3440 and $1650 \mathrm{~cm}^{-1}$. Figure 1(b, c, d) show the spectra of three absorbents after adsorbing AM and SY FCF. The absorption bands at $1650 \sim 1450 \mathrm{~cm}^{-1}$ and $900 \sim 600 \mathrm{~cm}^{-1}$ of aromatics and $1035 \mathrm{~cm}^{-1}$ of $-\mathrm{SO}_{3}{ }^{-}$ indicate that AM and SY FCF have been absorbed by these materials ${ }^{10}$.

Elemental analysis is employed to determine the mass fractions of composed elements. Mass fractions of carbon, hydrogen, nitrogen and oxygen are 58.5\%, $13.22 \%, 6.81 \%$ and $21.47 \%$ for PD; $58.60 \%, 10.08 \%, 9.32 \%$ and $22.00 \%$ for ED. The nitrogen contents are used to determine the quantity of PEI grafted on the PDMAEMA. The amount of PEI on the ED 5 is $5.93 \%$ calculated by Eq. 1 .

SEM images of PD, MD and ED are shown in Figure 3(a-c). Comparing with MD, the surfaces of PD and ED are dense and smooth. The rough and porous surface of MD is consistent with the findings of our previous research ${ }^{16}$. The SEM images of the polymer hydrogels after adsorption of dyes are shown in Figure 3(d-f). The comparison between before and after adsorption indicates the small particles of sunset yellow FCF have been attached onto these hydrogels surface. 

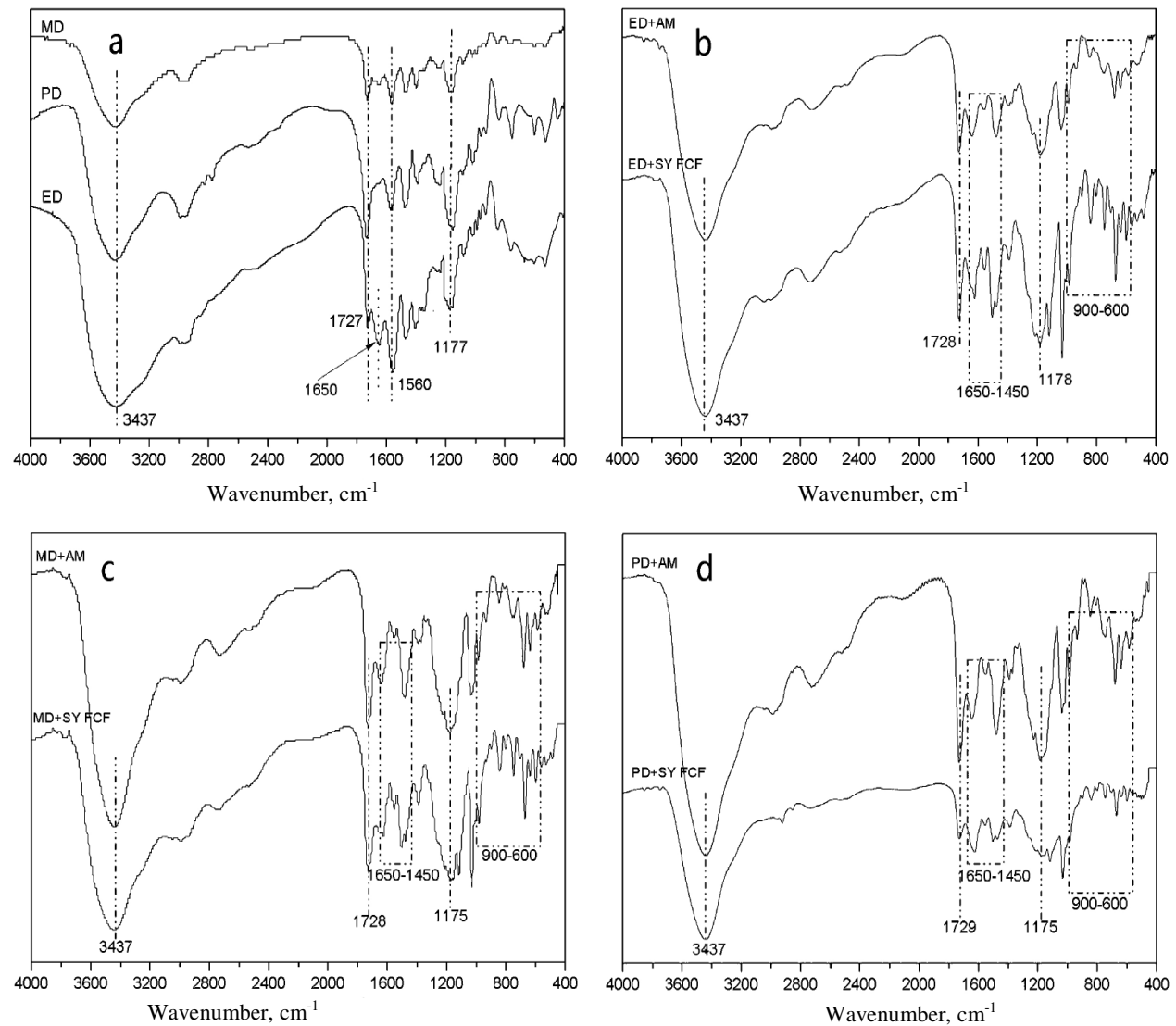

Figure 1. Infrared spectra of ED, MD, PD hydrogels before (a) and after adsorption of amaranth and sunset yellow FCF (b-d)

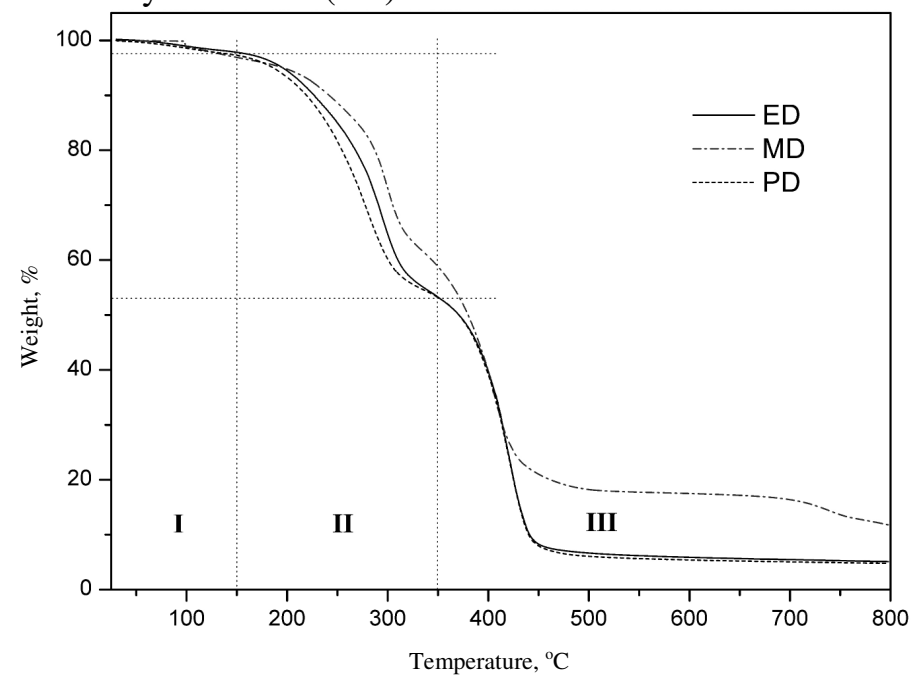

Figure 2. TGA of ED, MD and PD hydrogels 


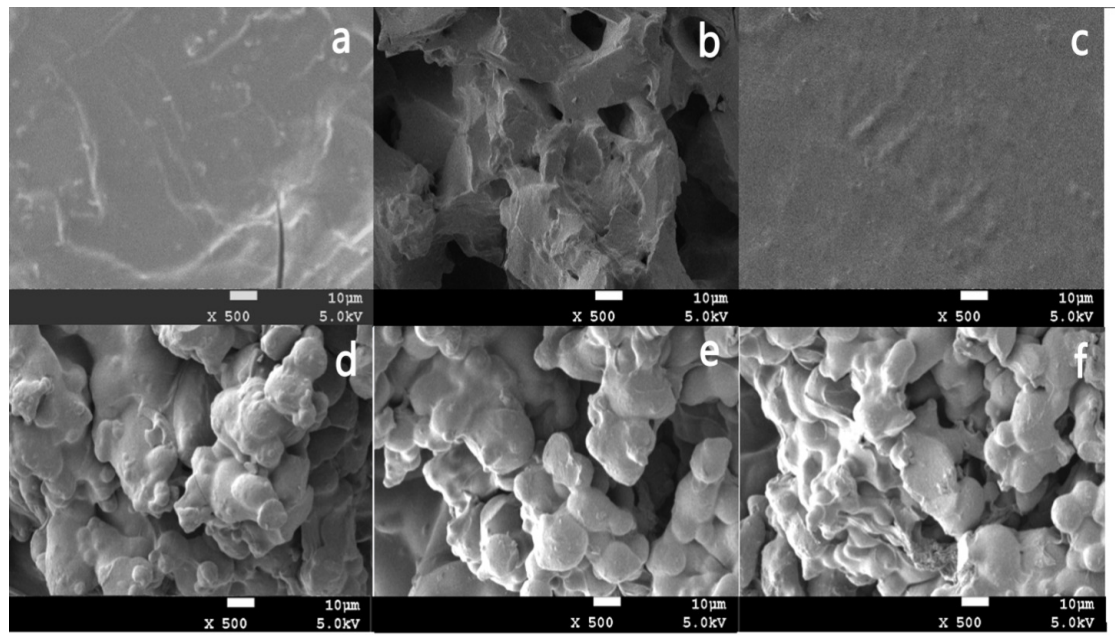

Figure 3. SEM images of ED, MD, PD hydrogels before and after adsorption of sunset yellow FCF, PD (a); MD (b); ED (c); PD+SY FCF (d); MD+SY FCF (e); ED+SY FCF (f)

The thermal stability was characterized by thermogravimetric analysis. TGA curves of $\mathrm{PD}, \mathrm{MD}$ and ED are shown in Figure 2. The decomposition process includes three sections. The first part (weight loss $2.5 \%$ between 30 and $150{ }^{\circ} \mathrm{C}$ ) can be attributed to evaporation of water adsorbed on the surface of gels. The next weight loss about $38.44 \%$ (MD), $44.68 \%$ (ED, PD) are observed between 150 and $500{ }^{\circ} \mathrm{C}$, the mass loss is likely due to decomposition of the amine groups. And the further degradation appears above $500{ }^{\circ} \mathrm{C}$ presumably because their backbones are attacked by the decomposed amine groups during the deamination reaction. The weight loss of these adsorbents is negligible below $150{ }^{\circ} \mathrm{C}$, indicating that these materials can be applied in high-temperature aqueous environment.

\section{Effect of contact time}

Figure 4 shows the effect of the contact time on the equilibrium uptakes of the PD, MD and ED materials. The results indicated that the adsorption curves of SY FCF and AM anions adsorbed by the same material were very similar. ED hydrogels exhibited the highest affinity for the anionic dyes and the equilibrium uptakes of SY FCF and AM were up to $757.10 \mathrm{mg} / \mathrm{g}$ and $744.14 \mathrm{mg} / \mathrm{g}$, respectively. The adsorption amount between PD and MD gels did not have a significant change. The uptakes of SY FCF and AM were 510.57 and $525.03 \mathrm{mg} / \mathrm{g}$ on MD gels, 475.23 and $501.43 \mathrm{mg} / \mathrm{g}$ on PD gels, respectively. The adsorption capacities of SY FCF and AM in previous studies are also summarized ${ }^{18-28}$ in Table 1. Comparing to other materials, the adsorption amount and rate of the MD and ED gels both have obvious advantages.

For the adsorption rate, the MD and ED gels were far higher than conventional PD gels. The equilibrium time was $5 \mathrm{~h}$ for the adsorption of dyes anions on conventional PD hydrogels, but it was only $2 \mathrm{~h}$ on the MD hydrogels and less than $60 \mathrm{~min}$ on the ED gels. The reasons could be assigned to the macroporous structures of MD gels, which could reduce the mass resistance of anionic dyes. With respect to ED gels, the introduction of PEI polymer increased the hydrophilicity of the gels and the amount of amide groups, which could make positive charged groups on the gels easier to contact with the anionic dyes under acidic conditions. 
Table 1. Comparison of $\mathrm{PD}, \mathrm{MD}$ and ED hydrogels adsorption capacity among different adsorbents

\begin{tabular}{|c|c|c|c|}
\hline $\begin{array}{c}\text { Anionic azo } \\
\text { dyes }\end{array}$ & Adsorbents [Ref] & $\begin{array}{c}\text { Adsorption } \\
\text { Capacities, } \mathrm{mg} \mathrm{g}^{-1}\end{array}$ & $\begin{array}{c}\text { Contact } \\
\text { time }\end{array}$ \\
\hline \multirow{15}{*}{$\begin{array}{c}\text { Sunset } \\
\text { Yellow FCF }\end{array}$} & Mangrove barks [9] & 12.72 & $5 \mathrm{~h}$ \\
\hline & Powdered peanut hull [18] & 13.99 & $36 \mathrm{~h}$ \\
\hline & Ag-NP-AC [19] & 37.03 & $30 \mathrm{~min}$ \\
\hline & Amberlite FPA51 [20] & 48.7 & $20 \mathrm{~min}$ \\
\hline & CdTN-AC [21] & 61.31 & $28 \min$ \\
\hline & $\mathrm{Cd}(\mathrm{OH})_{2}-\mathrm{NW}-\mathrm{AC}[19]$ & 76.9 & $25 \min$ \\
\hline & MPMWCNT nanocomposite [22] & 85.47 & $6 \mathrm{~h}$ \\
\hline & ePTFE-g-PDMAEMA [23] & 170.61 & - \\
\hline & $\mathrm{CaAl}-\mathrm{LDH}_{-}-\mathrm{NO}_{3}[24]$ & 398.41 & $50 \mathrm{~min}$ \\
\hline & PDVB-IL [10] & 734.62 & $5 \mathrm{~h}$ \\
\hline & PE-g-PDMAEMA [4] & 805.24 & $30 \mathrm{~h}$ \\
\hline & (PES/PEI) nanofibrous membrane [5] & 1000 & $10 \mathrm{~h}$ \\
\hline & Conventional poly(DMAEMA) (PD) & 501.43 & $5 \mathrm{~h}$ \\
\hline & Macroporous poly(DMAEMA) (MD) & 525.03 & $2 \mathrm{~h}$ \\
\hline & PEI-g-PDMAEMA (ED) & 744.14 & $1 \mathrm{~h}$ \\
\hline \multirow[t]{16}{*}{ Amaranth } & Iron oxide nanoparticles [25] & 1.05 & $5 \mathrm{~min}$ \\
\hline & Alumina Reinforced Polystyrene [6] & 8.281 & $2 \mathrm{~h}$ \\
\hline & Powdered peanut hull [18] & 14.9 & $36 \mathrm{~h}$ \\
\hline & Citrullus lanatus rind [7] & 23.0 & $3 \mathrm{~h}$ \\
\hline & MPMWCNT nanocomposite [22] & 47.39 & $6 \mathrm{~h}$ \\
\hline & $\mathrm{Fe}_{3} \mathrm{O}_{4} / \mathrm{ZrO}_{2} /$ chitosan [8] & 99.6 & $8 \mathrm{~h}$ \\
\hline & ePTFE-g-PDMAEMA [23] & 173.29 & - \\
\hline & Chitosan films [26] & 278.3 & $2 \mathrm{~h}$ \\
\hline & Cellulose Carbon Encapsulated $\mathrm{ZnO}$ [27] & 396 & $3 \mathrm{~h}$ \\
\hline & (PES/PEI) nanofibrous membrane [5] & 454.44 & $14 \mathrm{~h}$ \\
\hline & PDVB-IL [10] & 547.17 & $5 \mathrm{~h}$ \\
\hline & CSU-1(150) [28] & 650 & $24 \mathrm{~h}$ \\
\hline & PE-g-PDMAEMA [4] & 737.21 & $30 \mathrm{~h}$ \\
\hline & Conventional poly(DMAEMA (PD) & 475.23 & $5 \mathrm{~h}$ \\
\hline & Macroporous poly(DMAEMA) (MD) & 510.57 & $2 \mathrm{~h}$ \\
\hline & PEI-g-PDMAEMA (ED) & 757.10 & $1 \mathrm{~h}$ \\
\hline
\end{tabular}

Effect of initial concentration

Figure 5 shows the effect of the initial dye concentration on the equilibrium uptakes of the PD, MD and ED materials. The initial concentration was changed in the range of 200 1600 mg/L. The adsorption results showed that the adsorption capacity of SY FCF and AM could rise with the increasing concentration and ultimately attain a saturated value. The anionic dyes uptakes tended to level off when the dyes concentration exceeded $800 \mathrm{mg} / \mathrm{L}$ for the PD and MD gels, and $1000 \mathrm{mg} / \mathrm{L}$ for ED gels, respectively. The sulfonic acid groups on the SY FCF and AM with negative charges could interact with positive-charged groups by electrostatic interaction. Amino and imino groups on hydrogels compounded with PEI and dimethylamino groups on ED polymers could provide more adsorption sites, which was benefit for the adsorption. 


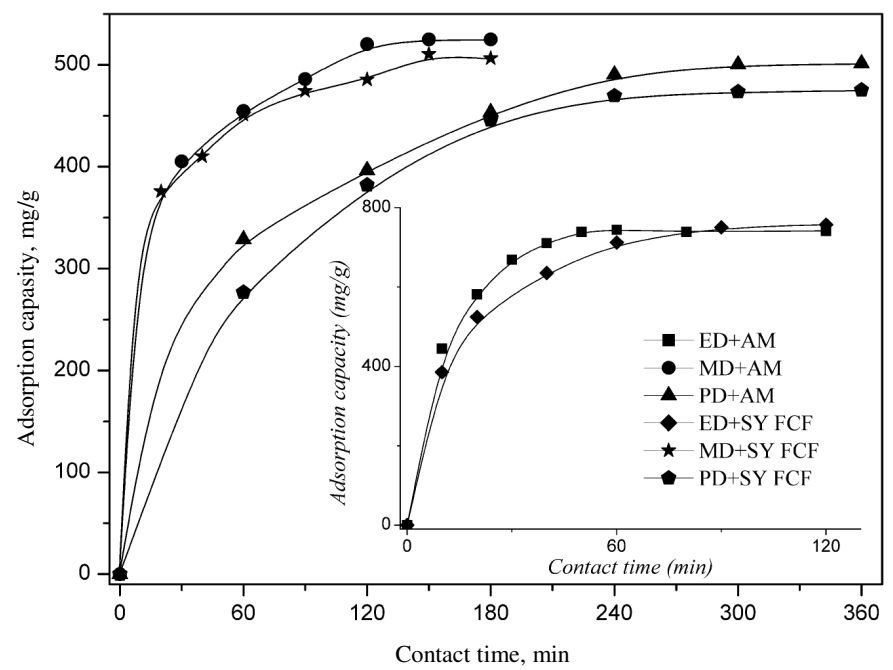

Figure 4. Effect of the contact time on the adsorption of the anionic dyes on ED, MD and PD hydrogels

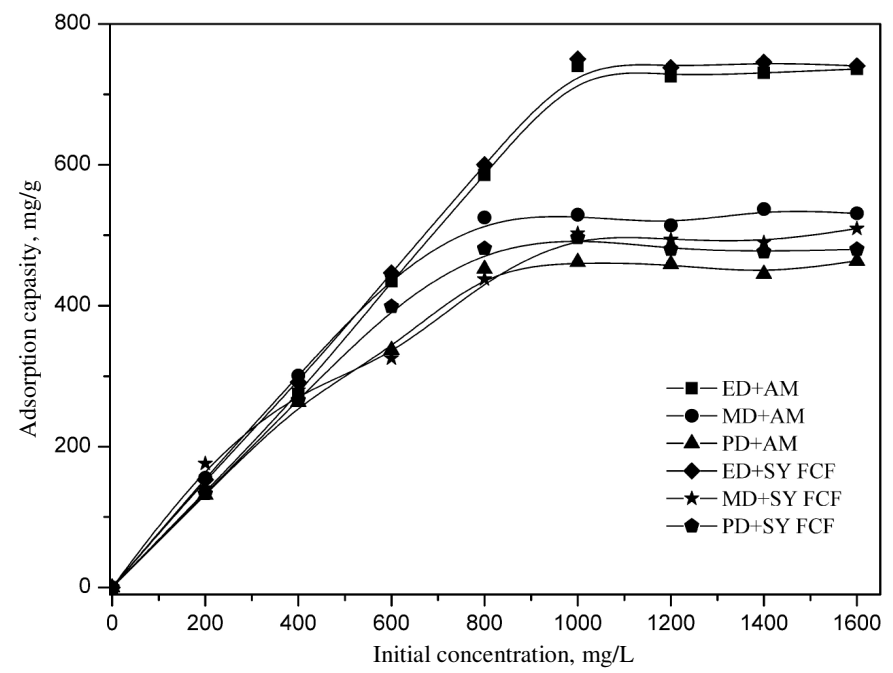

Figure 5. Effect of the initial concentration on the adsorption of the anionic dyes on ED, MD and PD hydrogels

\section{Effect of initial solution $\mathrm{pH}$}

The functional amino, imino and dimethylamino groups $\left(\uparrow \mathrm{NH}_{2}, \uparrow \mathrm{NH} \uparrow\right.$ and $\left.\uparrow \mathrm{NMe}_{2}\right)$ could turn into positive ammonium groups $\left(\uparrow \mathrm{NH}_{3}{ }^{+}, \uparrow \mathrm{NH}_{2}{ }^{+} \uparrow\right.$ and $\left.\uparrow \mathrm{NH}^{+} \mathrm{Me}_{2}\right)$ in the high proton surrounding. These positive-charged adsorption sites could strongly attract negative-charged dye anions by electrostatic attraction, so the anionic dyes in the acidic solution could be easily removed.

Figure 6 shows the effect of $\mathrm{pH}$ on equilibrium adsorption of the anionic dyes onto the gels. As shown in the figure, the uptakes of dyes were closely interrelated with the $\mathrm{pH}$ values of the dye solution and these curves could be divided into three stages. The first stage 
(1.0 2.0) was that the adsorption capacity of PD and MD gels slightly declined. But in the same stage, a tiny increase on the ED gel appeared. The likely reason was that the functional amino, imino and dimethylamino groups $\left(\uparrow \mathrm{NH}_{2}, \uparrow \mathrm{NH} \uparrow\right.$ and $\left.\uparrow \mathrm{NMe}_{2}\right)$ have been nearly protonated when $\mathrm{pH}$ value was 2.0 and continuing to improve the $\mathrm{H}^{+}$concentration, the positive-charged groups had not a obvious change. As for the nuance on the ED gels, it was due to the screening effect caused by the addition of $\mathrm{HCl}^{4}$. In the next stage (2.0 3.0), the uptakes of dyes on the adsorbents rapidly decreased. The reasonable explanation was that the amount of effective adsorption sites reduced rapidly with the decreasing protons concentration, eventually resulting in an increase of anionic dyes in the solution. In the range of 3.0 6.0, the adsorption amount of dyes went to zero asymptotically, because there were no enough protons to form active electropositive sites.

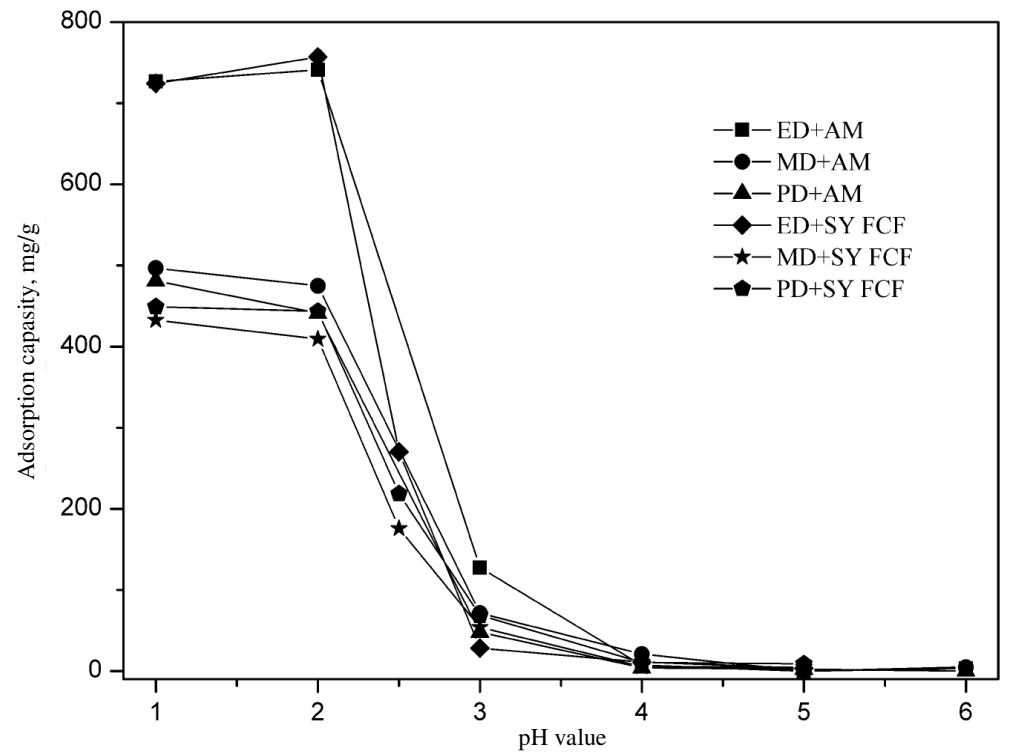

Figure 6. Effect of solution $\mathrm{pH}$ value on the adsorption of the anionic dyes on ED, MD and PD hydrogels

\section{Effect of solution temperature}

The impact of solution temperature on the equilibrium uptake was investigated at 30, 40 and $50{ }^{\circ} \mathrm{C}$. As shown in Figure 7, the adsorption capacity on these materials raised as the temperature increased, which indicated that the adsorption of dyes on these adsorbents was an endothermic process. The result could be attributed to the intensification of molecular thermodynamic movement. That is to say, adsorption of dyes anions on these materials was favored with high temperature, and the similar results were found for anionic dyes adsorption onto PES/PEI nanofibrous membrane ${ }^{6}$ and magnetic poly(HEMA-co-MMA) beads ${ }^{29}$.

\section{Effect of ionic strength and species}

Ionic strength is one of the major factors impacting the adsorption capacity of the gels by transforming the thickness of electrical double layer structure ${ }^{30}$. The results are shown in Figure 8. The sorption capacity obviously decreased with the increase of ionic strength, especially in the concentration range above $0.1 \mathrm{M}$. It was exactly because of the weakening of electrostatic interaction between the active adsorption sites and the acidic sulphonic groups of 
the dyes. For the presence of high concentration of $\mathrm{Na}^{+}$and $\mathrm{Cl}^{\uparrow}$ ions, it became increasingly difficult to further compress the electrical double layer surrounding the adsorbent surface. Thereby the removal ratio dropped with the increase of $\mathrm{NaCl}$ concentration.

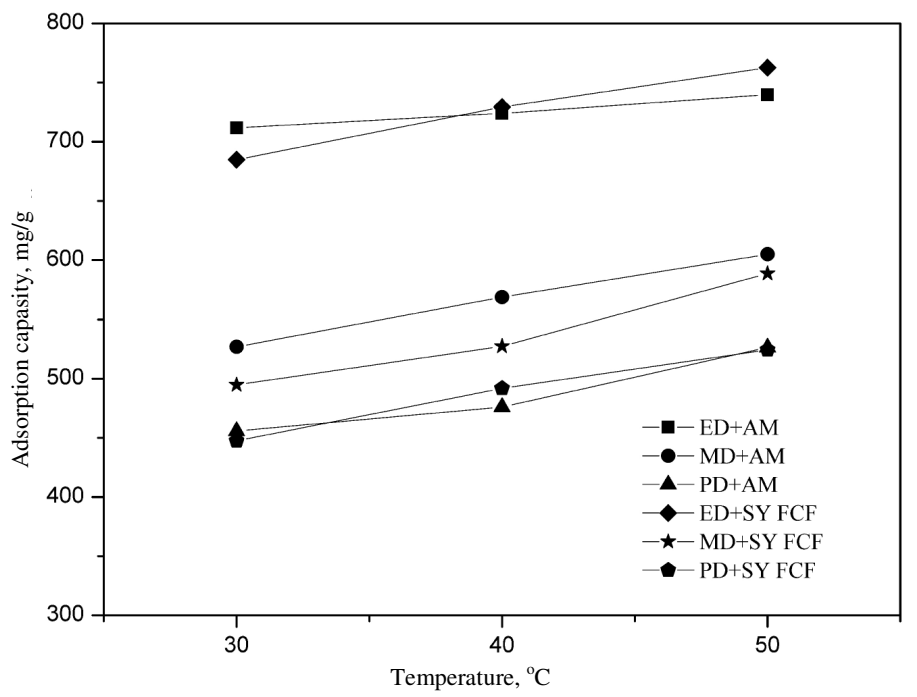

Figure 7. Effect of temperature on the adsorption of the anionic dyes on ED, MD and PD hydrogels

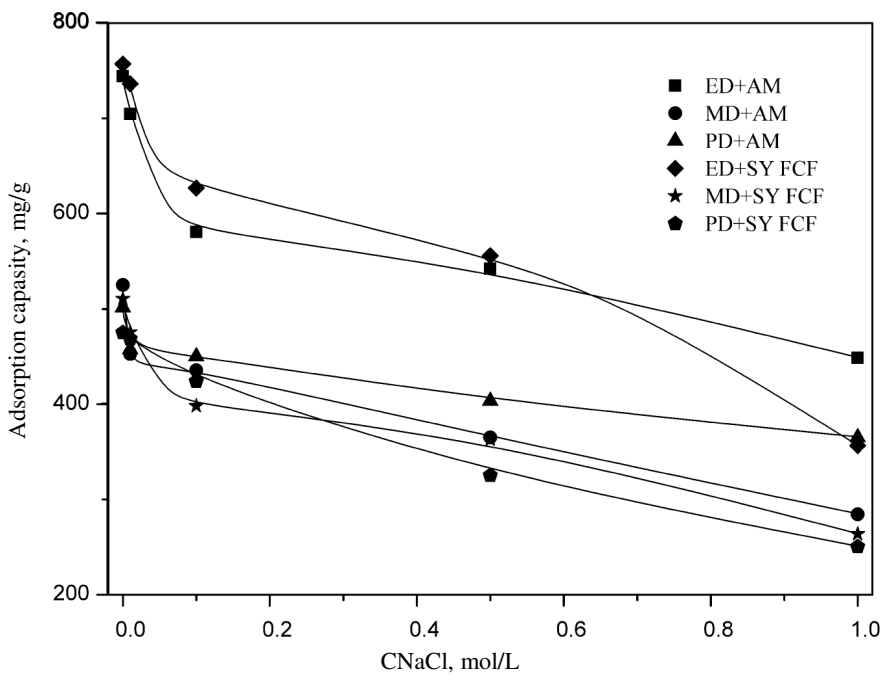

Figure 8. Effect of ionic strength on the adsorption of the anionic dyes on ED, MD and PD hydrogels

To determine further the influence of ionic species on the adsorption capacity, the inorganic salts were divided into cationic group $\left(\mathrm{Na}^{+}, \mathrm{K}^{+}, \mathrm{NH}_{4}^{+}\right)$and anionic group $\left(\mathrm{Cl}^{-}\right.$, $\left.\mathrm{NO}_{3}^{-}, \mathrm{SO}_{4}{ }^{2-}\right)$. The experiment result can be found in Figure 9. The influence of cations was weaker than that of anions at the same concentration. This could be attributed to the competition between the adding inorganic anions and the negatively charged sulphonic groups. Except $\mathrm{SO}_{4}{ }^{2-}$, there was no obvious difference in the effect of ionic species. 


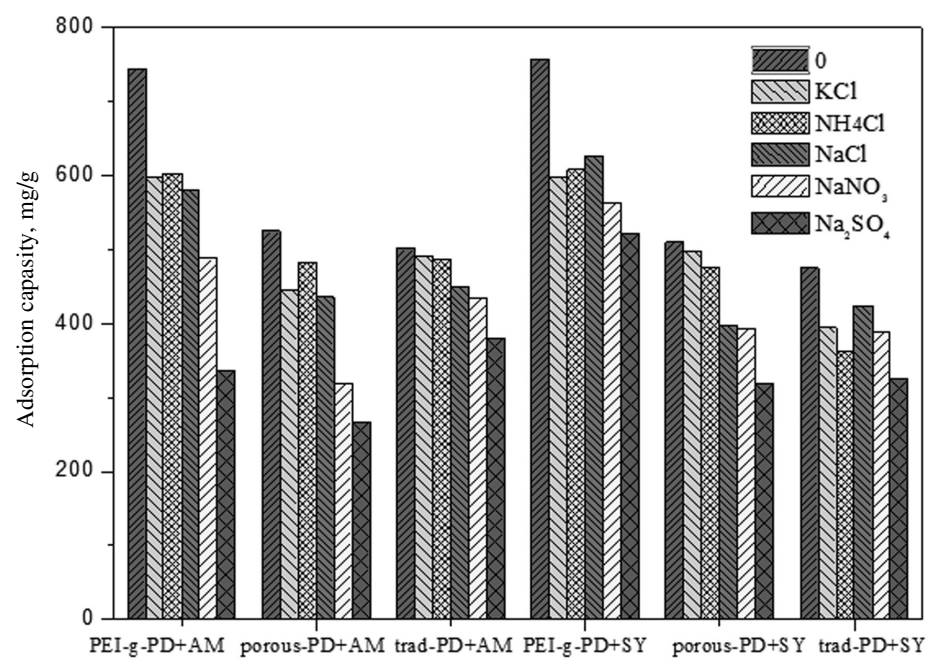

Figure 9. Effect of ionic species on the adsorption of the anionic dyes on ED, MD and PD hydrogen

\section{Adsorption isotherms}

The experimental data were analyzed by the linear Langmuir and Freundlich isotherms to understand the adsorption behavior and sorption mechanism. The Langmuir adsorption model is based on the assumption that the identical adsorption sites are distributed on the homogeneous surface of the adsorbent and the adsorbed layer is monolayer coverage ${ }^{31,32}$. The linearized form of Langmuir equation can be expressed by Eq. 5. The dimensionless separation factor $\left(R_{L}\right)$ is an essential character of Langmuir isotherm defined by Eq. 6., which can be used to assess the adsorption isotherm into different types as follows: favorable $(0<$ $\left.R_{L}<1\right)$, unfavorable $\left(R_{L}>1\right)$, linear relationship $\left(R_{L}=1\right)$ and irreversible $\left(R_{L}=0\right)^{33,34}$.

$$
\begin{aligned}
\frac{C_{e}}{Q_{e}} & =\frac{C_{e}}{Q_{m}}+\frac{1}{K_{L} Q_{m}} \\
R_{L} & =1 /\left(1+K_{L} C_{0}\right)
\end{aligned}
$$

Where, $C O$ and $C e(\mathrm{mg} / \mathrm{L})$ are the initial and equilibrium concentration of dyes in solution, respectively. $Q e(\mathrm{mg} / \mathrm{g})$ represents the adsorbed dye ions per unit mass of adsorbent at equilibrium. $Q_{m}(\mathrm{mg} / \mathrm{g})$ denotes the maximum adsorption amount of anionic dyes and $K_{L}$ is the Langmuir constant $(\mathrm{L} / \mathrm{mg})$.

Freundlich isotherm is the most important multisite adsorption isotherm for rough surfaces, which can be expressed by the exponential equation below:

$$
\ln Q_{e}=\ln K_{F}+\frac{\ln C_{e}}{n}
$$

It assumes that the adsorbate concentration on the interface increases with the rise of solution concentration ${ }^{31}$. Where $K_{F}(\mathrm{mg} / \mathrm{g})$ is the constant of Freundlich isotherm model, the slope $1 / n$ ranging between 0 and 1 is a measure of the adsorption intensity or surface heterogeneity which may become more heterogeneous when $1 / n$ gets close to zero ${ }^{32}$. The value of $1 / n<1$ reveals a normal Langmuir isotherm while $1 / n>1$ is suggests corresponding with Freundlich isotherm ${ }^{35}$. 
The Langmuir and Freundlich adsorption parameters calculated from the corresponding isotherms were presented in Table 2. The data demonstrated that the Langmuir isotherm with higher correlation coefficients $\left(R^{2} \geq 0.9948\right)$ values was more appropriate to describe the adsorption process of dyes on these hydrogels, which indicated the adsorption interface was a monolayer. The theoretical maximum absorption capacities of the hydrogels for anionic dyes were calculated by the slope of the Eq. 5. These values closely resembled the experimental data. Besides, all the values of $R_{L}$ for these processes were between 0 and 1 , and the $1 / n$ values were below 1 . In conclusion, the Langmuir isotherm gives a better fit to the experimental data than the Freundlich isotherm.

Table 2. Langmuir and Freundlich constants for the adsorption of the anionic dyes on $\mathrm{PD}, \mathrm{MD}$ and ED hydrogels

\begin{tabular}{|c|c|c|c|c|c|c|c|}
\hline \multirow{2}{*}{$\begin{array}{c}\text { Adsorption } \\
\text { behavior }\end{array}$} & \multicolumn{4}{|c|}{ Langmuir constants } & \multicolumn{3}{|c|}{ Freundlich constants } \\
\hline & $\mathrm{Q}_{\mathrm{m}}, \mathrm{mg} / \mathrm{g}$ & $\mathrm{K}_{\mathrm{L}}, \mathrm{L} / \mathrm{mg}$ & $\mathrm{R}^{2}$ & $\mathrm{R}_{\mathrm{L}}$ & $\mathrm{K}_{\mathrm{F}}, \mathrm{mg} / \mathrm{g}$ & $1 / \mathrm{n}$ & $\mathrm{R}^{2}$ \\
\hline $\mathrm{ED}+\mathrm{AM}$ & 751.88 & 0.084018 & 0.9987 & $\begin{array}{c}0.05617- \\
0.00738\end{array}$ & 57.5636 & 0.42066 & 0.7025 \\
\hline M & & 0.0 & 0.9 & $\begin{array}{c}0.15584- \\
0.02256\end{array}$ & 16 & 16 & 07 \\
\hline PD & 465 & 0.07 & 0.9981 & $\begin{array}{r}0.061 \\
0.00\end{array}$ & 132.4851 & 0.20202 & 0.7864 \\
\hline $\mathrm{ED}+\mathrm{s}$ & 757 & 0.09 & 0.9978 & $\begin{array}{c}0.05074- \\
0.00664\end{array}$ & 158.3060 & 0.25826 & 0.9192 \\
\hline MD+SY FCF & 520.83 & 0.026162 & 0.9948 & $\begin{array}{c}0.160450- \\
02333\end{array}$ & 158.6150 & 0.16633 & 0.8898 \\
\hline PD+SY FCF & 480.77 & 0.83871 & 0.9998 & $\begin{array}{c}0.00593- \\
0.00074\end{array}$ & 193.6050 & 0.15478 & 0.6049 \\
\hline
\end{tabular}

\section{Adsorption kinetics}

In order to investigate the mechanism and rate controlling steps of adsorption, both the pseudo-first order and the pseudo-second order $^{36}$ kinetic models were applied to analyze adsorption data. The pseudo-first order model is based on an assumption that the percentage of the adsorption sites occupied by dyes anions is proportional to the amount of unoccupied sites $^{37}$. The equation of the model is expressed as following:

$$
\ln \left(Q_{e}-Q_{t}\right)=\ln Q_{e}-k_{1} t
$$

Where $Q_{e}$ and $Q_{t}$ refer to the amount of dye adsorbed $(\mathrm{mg} / \mathrm{g})$ at equilibrium and a given time $(t, \mathrm{~min})$, respectively and $k_{l}$ is the rate constant of pseudo-first order adsorption $(1 / \mathrm{min})$. The experimental data were also analyzed according to the pseudo-second order kinetic, which regards the formation of chemisorptive bond as the adsorption rate limiting step $^{38}$. The pseudo-second order rate constant, namely $k_{2}$, can be calculated by the slopes of the linear plot of $t / Q_{t}$ versus $t$, described by the Eq 9 .

$$
\frac{t}{Q_{t}}=\frac{1}{k_{2} Q_{e}^{2}}+\frac{t}{Q_{e}}
$$

As it can be seen in Table 3, all of the correlation coefficient values of pseudo-second order kinetic model are above 0.9945 . However, these values of pseudo-first order model are well below the former. The theoretical $Q e$ values obtained from the pseudo-second order 
equation is consistent with the experimental $Q e$, which is rather less obvious for the pseudofirst order model. Clearly, the pseudo-second order kinetic model was more suitable depicting the adsorption data of dyes on these composite gels. So it could be concluded that the interaction between the protonated nitrogen functional groups and the sulfonic acid groups should be the rate-determining step (RDS).

Table 3. Adsorption kinetic parameters for the adsorption of the anionic dyes on PD, MD and ED hydrogels

\begin{tabular}{cccccccc}
\hline & & \multicolumn{3}{c}{ Pseudo-first order model } & \multicolumn{3}{c}{ Pseudo-second order model } \\
\cline { 3 - 8 } $\begin{array}{c}\text { Adsorption } \\
\text { behavior }\end{array}$ & $\begin{array}{c}\mathrm{Q}_{\mathrm{e} . \exp } \mathrm{mg} / \mathrm{g} \\
\mathrm{k}_{1}\end{array}$ & $\begin{array}{c}\mathrm{k}_{1} \\
\mathrm{~min}^{-1}\end{array}$ & $\begin{array}{c}\mathrm{Q}_{\mathrm{e}} \\
\mathrm{mg} / \mathrm{g}\end{array}$ & $\mathrm{R}^{2}$ & $\begin{array}{c}\mathrm{K}_{2} \\
\mathrm{~g} / \mathrm{mg} \mathrm{min}^{-1} \\
\times 10^{4}\end{array}$ & $\begin{array}{c}\mathrm{Q}_{\mathrm{e}} \\
\mathrm{mg} / \mathrm{g}\end{array}$ & $\mathrm{R}^{2}$ \\
\hline ED+AM & 744.14 & 0.09182 & 876.89 & 0.9510 & 2.2878 & 787.4016 & 0.9972 \\
MD+AM & 525.03 & 0.03510 & 498.43 & 0.9176 & 1.3277 & 568.1818 & 0.9987 \\
PD+AM & 501.43 & 0.01882 & 704.53 & 0.9197 & 0.3685 & 574.7126 & 0.9976 \\
ED+SY FCF & 757.10 & 0.04960 & 715.16 & 0.9851 & 1.0122 & 840.3361 & 0.9993 \\
MD+SY FCF 510.57 & 0.02359 & 308.04 & 0.9494 & 1.6770 & 537.6344 & 0.9987 \\
PD+SY FCF & 475.23 & 0.01910 & 643.23 & 0.9773 & 0.3340 & 558.6592 & 0.9945 \\
\hline
\end{tabular}

\section{Adsorption mechanisms}

Adsorption in multi-component systems is a very complicated process because of so many solute-surface interactions involved ${ }^{39}$. In Qafoku et al's study ${ }^{40}$, the interaction model of the electrical double layers was used to explain the mechanism of adsorption of the cations and anions. Based on electrical double layer theory of Stern, an electrical phenomenon on the surface could influence the species distributions in the surrounding to form Stern layer (compact layer) and Gou layer(external diffusion layer), when the solid contacts with liquid $^{41}$. For PD, MD, ED, the functional amino, imino and dimethylamino groups $\left(\uparrow \mathrm{NH}_{2}\right.$, $\uparrow \mathrm{NH} \uparrow$ and $\uparrow \mathrm{NMe}_{2}$ ) could combined with $\mathrm{H}^{+}$ionized in solution by hydrogen bonding to get the positively charged particles. The SY FCF and AM could ionize in solution to obtain the anionic groups. When the polymers were dispersed in the dye solution, an interaction between electrical double layers on the positively charged polymers and the negatively charged dyes may occur, which led to a decrease in effective surface charge density of the polymer $^{42}$ (Figure 12). This could help explain the phenomenon in Figure 10 that, after adsorption, the volume of the adsorbents shriveled, caused by the density of co-ions reducing. In addition, according to Stern's study, the adsorption on Stern layer satisfied Langmuir monolayer adsorption model, which was in accord with our above isotherms result. According to the above analysis, the plausible adsorption process of dyes anions onto the polymers was shown in Figure 13.

\section{Desorption}

Not only the adsorption capacity but also the reusability is used to evaluate the potential practical application of a candidate adsorbent. The desorption performance has a close relation to the regeneration of the sorbents. According to the preceding experiment results, the $\mathrm{pH}$ value of the solution was the major constraint on the electrostatic attractions between protonated dimethylamino groups and anionic dyes and the higher $\mathrm{pH}$ value was unfavorable for adsorption. Therefore, $0.1 \mathrm{~mol} / \mathrm{LNaOH}$ solution was chosen as an effective regeneration solution. In order to improve the desorption effect; the dyes on the hydrogels 
were desorbed for $30 \mathrm{~min}$ by $5 \mathrm{~mL}$ alkali liquor twice. The process and result are shown in Figure 10 and Figure 11, respectively. The elution efficiency after second adsorption reached about $95 \%$ and the total recovery ratios were above $92.73 \%$. In order to get a satisfactory elution result, the concentration of dyes in the eluent should be controlled below $2 \mathrm{mg} / \mathrm{mL}$. These results could prove that these adsorbing materials could effectively recover their adsorption capacity and had a good economic characteristic.

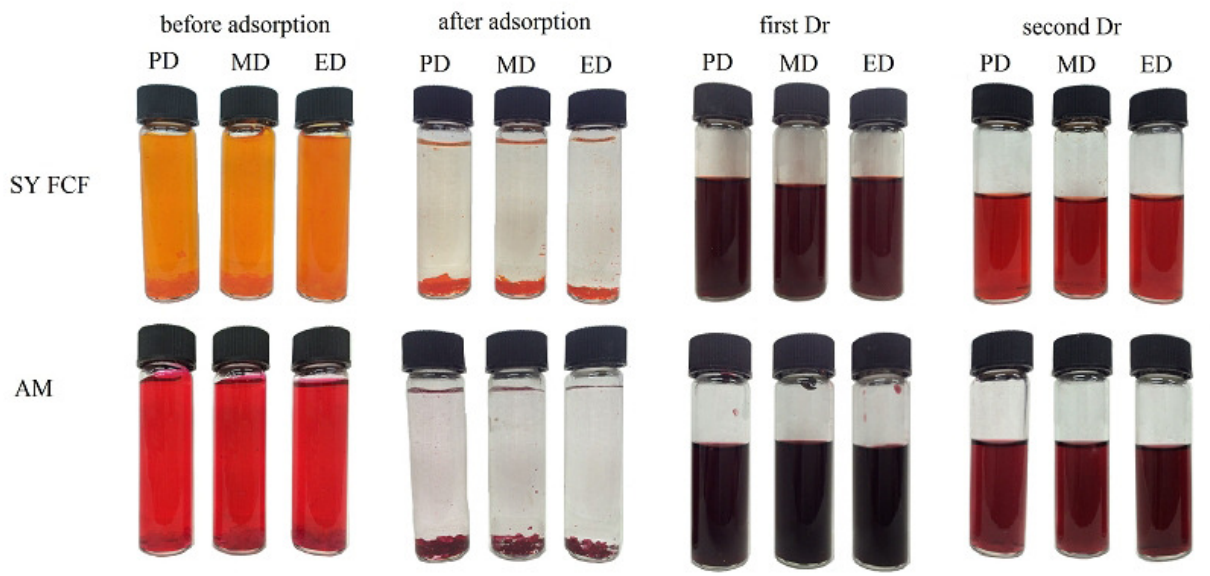

Figure 10. The process of adsorption and desorption of anionic dyes on ED, MD and PD hydrogels

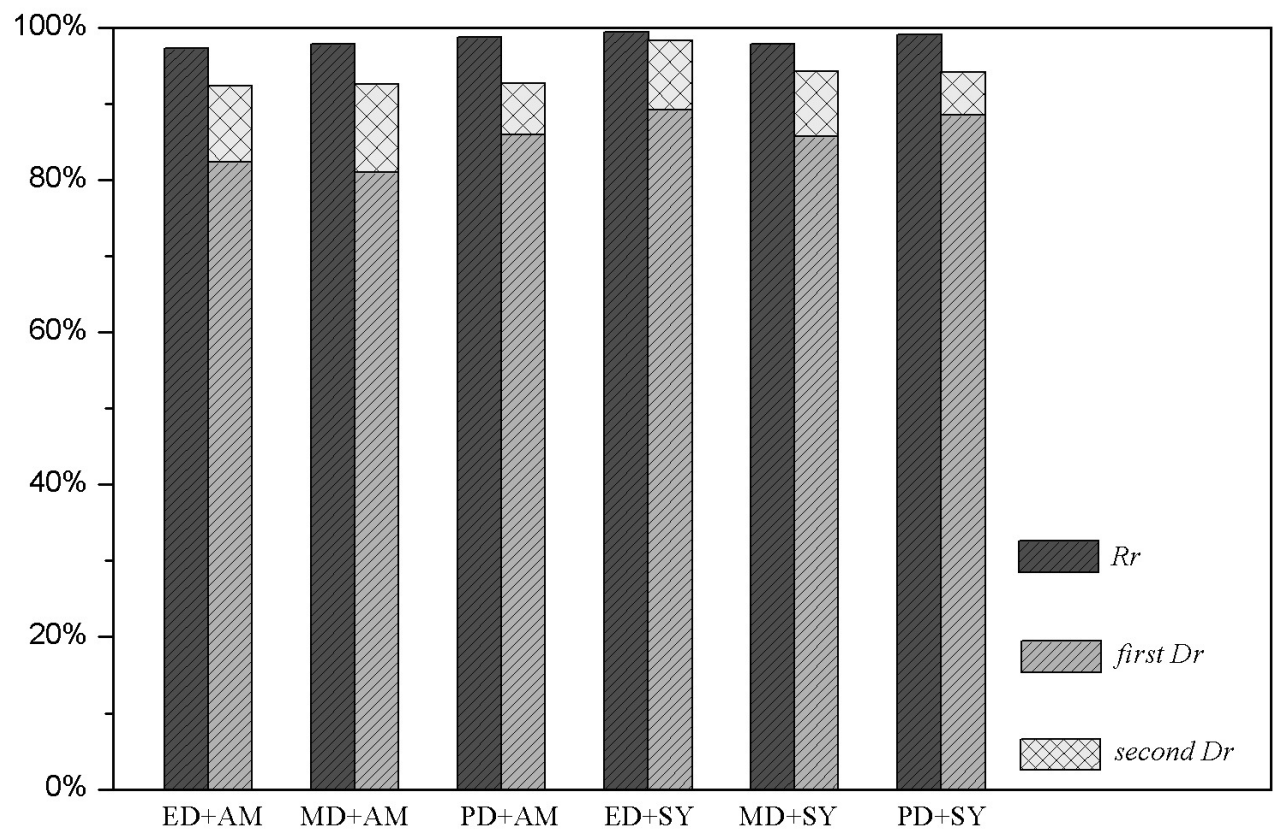

Figure 11. Adsorption and desorption of anionic dyes on ED, MD and PD hydrogels, adsorption condition: initial concentration of dyes $200 \mathrm{mg} / \mathrm{L}, \mathrm{pH} 2.0$ and $30{ }^{\circ} \mathrm{C}$ desorption condition: $2 \times 5 \mathrm{~mL} 0.1 \mathrm{M} \mathrm{NaOH}, 30 \mathrm{~min}$ 


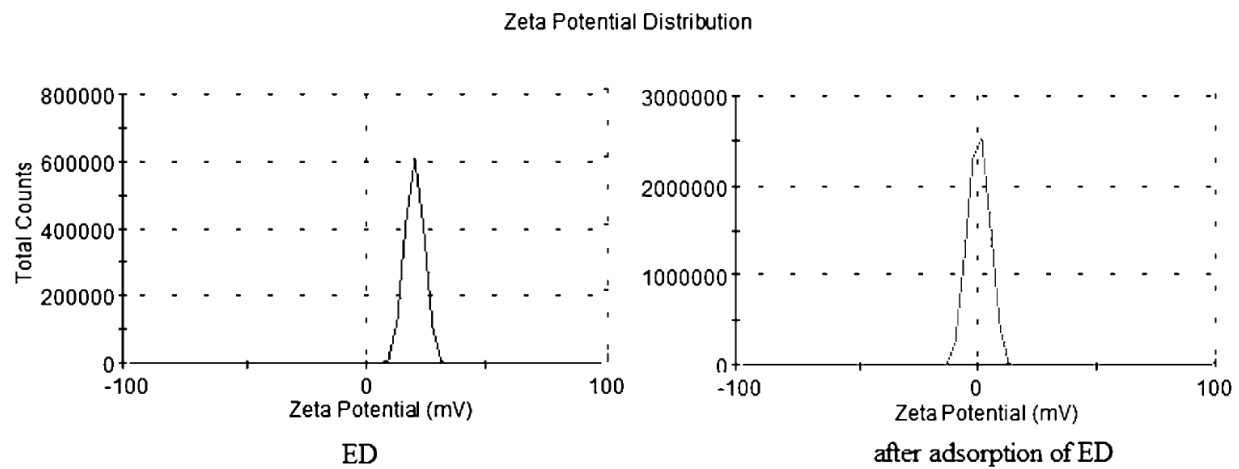

Figure 12. Zeta potential distribution of ED and after adsorption of ED

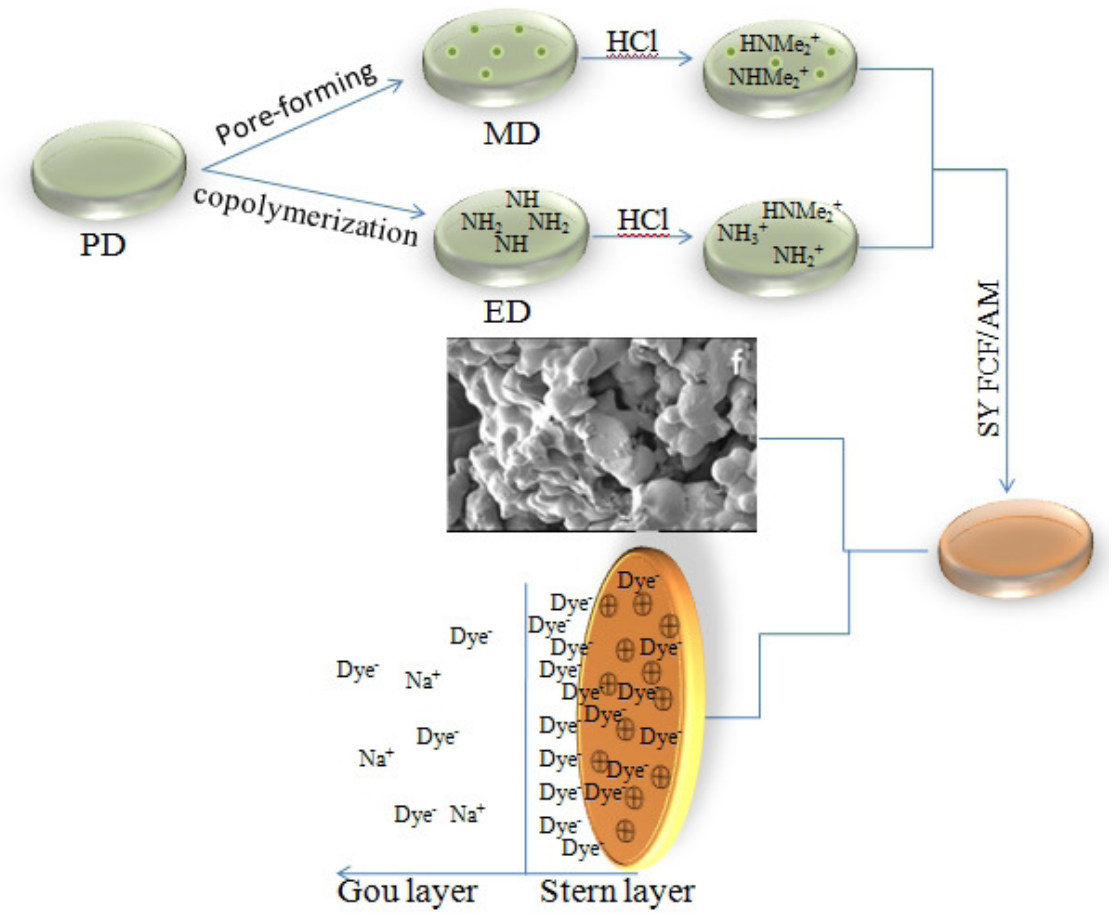

Figure 13. The plausible adsorption processes of dyes anions onto the polymers

\section{Conclusion}

This work presented the adsorption of anionic dyes on three types of hydrogels based on the PDMAEMA skeletal structure. The amount of dyes adsorbed was found to be dependent on solution $\mathrm{pH}$, initial dyes concentration, contact time, temperature, ionic strength and species. From the experimental results mentioned previously, we could draw the following conclusions:

(1) The maximum adsorption capacity of ED, MD and PD gels were $744.14 \mathrm{mg} / \mathrm{g}, 525.03 \mathrm{mg} / \mathrm{g}$ and $501.43 \mathrm{mg} / \mathrm{g}$ for SY FCF, $757.10 \mathrm{mg} / \mathrm{g}, 510.57 \mathrm{mg} / \mathrm{g}$ and $475.23 \mathrm{mg} / \mathrm{g}$ for AM, respectively. 
(2) MD gels could reduce the equllibrium adsorption time from $5 \mathrm{~h}$ to $2 \mathrm{~h}$, but the adsorption amount did not increase; however, ED gels could improve both the adsorption rate and capacity.

(3) The adsorption capacity gradually decreased with the increase of $\mathrm{pH}$ and the amount of effective adsorption sites reduced significantly with the decreasing protons concentration.

(4) The adsorption behaviors were well fitted with the Pseudo-second order kinetic and Langmuir isotherm models. It indicated that the adsorbed layer was monolayer coverage and electrostatic interaction between anions and gels played a dominating role in the adsorption process.

(5) High temperature and low ionic strength were conducive to the adsorption of dyes on hydrogels. Ionic species was also an influence factor and anions had a greater effect than cations, with $\mathrm{SO}_{4}{ }^{2-}$ in particular.

(6) Alkali liquor could effectively regenerate hydrogels, which had good economic andrecycling characteristic.

\section{References}

1. Jing G, Wang L, Yu H, Amer W and Zhang L, Colloids Surfaces A: Physicochem Eng Aspects, 2013, 416, 86-94; DOI:10.1016/j.colsurfa.2012.09.043

2. Aguedach A, Brosillon S, Morvan J and Lhadi K, J Hazard Mater., 2008, 150(2), 250-256; DOI:10.1016/j.jhazmat.2007.04.086

3. Libra J A, Borchert M, Vigelahn L and Storm T, Chemosphere, 2004, 56(2), 167-180; DOI:10.1016/j.chemosphere.2004.02.012

4. Yamada K, Shibuya M, Takagi C and Hirata M, J Appl Polym Sci., 2006, 99(1), 381391; DOI:10.1002/app.22477

5. Min M, Shen L, Hong G, Zhu M, Zhang Y, Wang X, Chen Y and Hsiao B S, Chem Eng J., 2012, 197, 88-100; DOI:10.1016/j.cej.2012.05.021

6. Ahmad R and Kumar R, Clean Soil Air, Water, 2011, 39(1), 74-82; DOI:10.1002/clen.201000125

7. Suyamboo B K and Perumal R S, Iran J Energy Environ., 2012, 3(1), 23-34; DOI: 10.5829/idosi.ijee.2012.03.01.0130

8. Jiang H, Chen P, Luo S, Luo X, Tu X, Cao Q, Zhou Y and Zhang W, J Inorg Organomet Polym., 2012, 23, 393-400; DOI:10.1007/s10904-012-9792-7

9.. $\quad$ Seey T L and Kassim M, Int J Appl Sci Technol., 2012, 2, 270-276.

10. Gao H, Zhao S, Cheng X, Wang X and Zheng L, J Hazard. Mater., 2013, 261, 83-90; DOI:10.1016/j.jhazmat.2013.07.001

11. Malek A H A and Yasin Y, Chem Sci Trans., 2012, 1, 194-200; DOI:10.7598/cst2012.120

12. Tokuyama $\mathrm{H}$ and Ishihara N, React Funct Polym., 2010, 70(9), 610-615; DOI:10.1016/j.reactfunctpolym.2010.05.005

13. Şolpan D, Şen M, Kölge Z and Güven O, Radiat Phys Chem., 2008, 77(4), 428-433; DOI:10.1016/j.radphyschem.2007.06.011

14. Cheng Q, Li C, Li J and Zhai M, Chem Eng J., 2011, 173, 42-48; DOI:10.1016/j.cej.2011.07.033

15. Yu W, Zhang L, Wang $\mathrm{H}$ and Chai L, J Hazard Mater., 2013, 260, 789-795; DOI:10.1016/j.jhazmat.2013.06.045

16. Zhu W X, Song H, Du K F, Zeng H and Yao S, J Appli Polym., 2013, 128(5), 27292735; DOI:10.1002/app.38409 
17. Chen Y, Xu W, Xiong Y, Peng C, Liu W, Zeng G and Peng Y, J Mater Res., 2013, 28(10), 1394-1404; DOI:10.1557/jmr.2013.82

18. Gong R, Ding Y, Li M, Yang C, Liu H and Sun Y, Dyes Pigments, 2005, 64(3), 187192; DOI:10.1016/j.dyepig.2004.05.005

19. Ghaedi M, Spectrochim Acta A Mol Biomol Spectrosc., 2012, 94, 346-351; DOI:10.1016/j.saa.2012.02.097

20. Wawrzkiewicz M, Environ Technol., 2011, 32(4), 455-465; DOI:10.1080/09593330.2010.502188

21. Ghaedi M, Hekmati Jah A, Khodadoust S, Sahraei R, Daneshfar A, Mihandoost A, Purkait M K, Spectrochim Acta A Mol Biomol Spectrosc., 2012, 90, 22-27; DOI:10.1016/j.saa.2011.12.064

22. Gao H, Zhao S, Cheng X, Wang X and Zheng L, Chem Eng J., 2013, 223, 84-90; DOI:10.1016/j.cej.2013.03.004

23. Yamada K, Takagi C and Hirata M, J Appl Polym Sci., 2007, 104, 3301-3308; DOI:10.1002/app.26131

24. de Sá F P, Cunha B N and Nunes L M, Chem Eng J., 2013, 215-216, 122-127; DOI:10.1016/j.cej.2014.03.035

25. Zargar B, Parham $\mathrm{H}$ and Hatamie A, Chemosphere, 2009, 76(4), 554-557; DOI:10.1016/j.chemosphere.2009.02.065

26. Rego T V, Cadaval T R, Jr, Dotto G L and Pinto L A, J Colloid Interface Sci., 2013, 411, 27-33; DOI:10.1016/j.jcis.2013.08.051

27. Ahmad R and Kumar R, J Disper Sci Tech., 2011, 32(5), 737-740.

28. Li J L, Li B T, Wang H C, Bian X B and Wang X M, Carbon, 2011, 49, 1912-1918.

29. Bayramoglu G, Altintas B and Arica M Y, J Chem Technol Biotechnol., 2012, 87(5), 705-713; DOI: $10.1002 /$ jctb.3693

30. Weng C H and Pan Y F, Colloids Surfaces A, 2006, 274(1-3), 154-162; DOI:10.1016/j.colsurfa.2005.08.044

31. Coskun R and Delibas A, Polym Bull., 2012, 68, 1889-1903; DOI:10.1007/s00289011-0664-Z

32. Liu Y, Zheng Y and Wang A, J Environ Sci., 2010, 22(4), 486-493; DOI:10.1016/S1001-0742(09)60134-0

33. Hall K R, Eagleton L C, Acrivos A and Vermeulen T, Ind Eng Chem Fund., 1966, 5(2), 212-223; DOI:10.1021/i160018a011

34. Guclu G and Keles S, J Appl Polym Sci., 2007, 106(4), 2422-2426;

DOI:10.1002/app.26778

35. Haghseresht F and Lu G Q, Energ Fuel., 1998, 12(6), 1100-1107;

DOI:10.1021/ef9801165

36. Lagergren S and Svenska B K, Vetenskaps Akad Handlingar, 1898, 24, 1-39.

37. Iftikhar A R, Bhatti H N, Hanif M A and Nadeem R, J Hazard Mater., 2009, 161, 941-947; DOI:10.1016/j.jhazmat.2008.04.040

38. Özacar M, Şengil I A and Türkmenler H, Chem Eng J., 2008, 143(1), 32-42; DOI:10.1016/j.cej.2007.12.005

39. Pereira F V, Gurgel L and Gil L. J Hazard Mater., 2010, 176(1-3), 856-863; DOI:10.1016/j.jhazmat.2009.11.115

40. Qafoku N, Ranst E V and Noble A, Adv Agron., 2004, 84, 159-215; DOI:10.1016/S0065-2113(04)84004-5

41. Stern O, Zeit Elektrochem., 1924, 30, 508-516.

42. Hou $\mathrm{T}, \mathrm{Xu} \mathrm{R}$ and Tiwari D, J Coll Inter Sci., 2007, 310(2), 670-674; DOI:10.1016/j.jcis.2007.02.035 